\title{
Effect of Early vs Late Start of Oral Intake on Anastomotic Leakage Following Elective Lower Intestinal Surgery
}

Citation for published version (APA):

Smeets, B. J. J., Peters, E. G., Horsten, E. C. J., Weijs, T. J., Rutten, H. J. T., Buurman, W. A., de Jonge, W. J., \& Luyer, M. D. P. (2018). Effect of Early vs Late Start of Oral Intake on Anastomotic Leakage Following Elective Lower Intestinal Surgery: A Systematic Review. Nutrition in Clinical Practice, 33(6), 803-812. https://doi.org/10.1177/0884533617711128

Document status and date:

Published: 01/12/2018

DOI:

10.1177/0884533617711128

Document Version:

Publisher's PDF, also known as Version of record

Document license:

Taverne

Please check the document version of this publication:

- A submitted manuscript is the version of the article upon submission and before peer-review. There can be important differences between the submitted version and the official published version of record.

People interested in the research are advised to contact the author for the final version of the publication, or visit the DOI to the publisher's website.

- The final author version and the galley proof are versions of the publication after peer review.

- The final published version features the final layout of the paper including the volume, issue and page numbers.

Link to publication

\footnotetext{
General rights rights.

- You may freely distribute the URL identifying the publication in the public portal. please follow below link for the End User Agreement:

www.umlib.nl/taverne-license

Take down policy

If you believe that this document breaches copyright please contact us at:

repository@maastrichtuniversity.nl

providing details and we will investigate your claim.
}

Copyright and moral rights for the publications made accessible in the public portal are retained by the authors and/or other copyright owners and it is a condition of accessing publications that users recognise and abide by the legal requirements associated with these

- Users may download and print one copy of any publication from the public portal for the purpose of private study or research.

- You may not further distribute the material or use it for any profit-making activity or commercial gain

If the publication is distributed under the terms of Article $25 \mathrm{fa}$ of the Dutch Copyright Act, indicated by the "Taverne" license above, 


\title{
Effect of Early vs Late Start of Oral Intake on Anastomotic Leakage Following Elective Lower Intestinal Surgery: A Systematic Review
}

Nutrition in Clinical Practice

Volume 33 Number 6

December 2018 803-812

(c) 2017 American Society for

Parenteral and Enteral Nutrition DOI: $10.1177 / 0884533617711128$ wileyonlinelibrary.com

WILEY

\author{
Boudewijn J. J. Smeets, MD ${ }^{1,2}$; Emmeline G. Peters, MD $^{1,3}$; \\ Eelco C. J. Horsten, BSc ${ }^{1}$; Teus J. Weijs, PhD $^{1}$; Harm J. T. Rutten, $\mathbf{P h D}^{1,2}$; \\ Willem A. Buurman, $\mathrm{PhD}^{4}$; Wouter J. de Jonge, $\mathrm{PhD}^{3}$; and Misha D. P. Luyer, $\mathrm{PhD}^{1}$
}

\begin{abstract}
Background: Experimental and clinical studies have demonstrated a beneficial effect of early enteral nutrition (EN) on anastomotic leakage following colorectal surgery. Early oral intake is a common form of early EN with various clinical benefits, but the effect on anastomotic leakage is unclear. This systematic review investigates the effect of early vs late start of oral intake on anastomotic leakage following lower intestinal surgery. Methods: A systematic literature search was performed using the PubMed, Embase, Medline, and Cochrane databases. Randomized controlled trials were included that compared early (within 24 hours) vs late start of oral intake following elective surgery of the small bowel, colon, or rectum. Meta-analysis was performed for anastomotic leakage, overall complications, length of stay, and mortality. Sensitivity analysis was performed in which studies of inferior methodological quality were excluded. Results: Nine studies including 879 patients met eligibility criteria. Early start of oral intake significantly reduced overall complications (odds ratio [OR], 0.65; 95\% confidence interval [CI], 0.46-0.93; $P=.02$ ), length of stay (mean difference, $-0.89 ; 95 \% \mathrm{CI},-1.22$ to $-0.57 ; P<.001)$, and anastomotic leakage (OR, $0.40 ; 95 \% \mathrm{CI}, 0.17-0.95 ; P=.04)$ compared with late start of oral intake. However, in the sensitivity analysis only the overall reduction of length of stay remained significant. Conclusion: The effect of early oral intake on anastomotic leakage is unclear as existing studies are heterogeneous and at risk of bias. High-quality studies are needed to study the potential benefit of EN on anastomotic healing. (Nutr Clin Pract. 2018;33:803-812)
\end{abstract}

\section{Keywords}

enteral nutrition; surgery; wound healing; nutritional support; colorectal surgery; anastomotic leak; length of stay; mortality; metaanalysis

Anastomotic leakage (AL) is a severe complication following colorectal surgery as it is associated with increased morbidity, mortality, and cancer recurrence rates. ${ }^{1-4}$ Despite ongoing efforts, strategies that effectively reduce AL are lacking and the incidence has remained stable over the years. $^{5}$

Several experimental studies have demonstrated that enteral nutrition (EN) may improve anastomotic healing. ${ }^{6-12}$ Moreover, in 2 recent randomized controlled trials, AL following colorectal surgery was significantly reduced by means of early postoperative $\mathrm{EN}^{13}$ and direct perioperative sham feeding. ${ }^{14}$ Taken together, these results suggest that EN administered close to surgery may provide new therapeutic opportunities to reduce AL.

A common method to provide EN close to surgery is the early postoperative start of oral intake. Systematic reviews on the effects of early start of oral intake following gastrointestinal (GI) surgery have demonstrated clear benefits, including a reduction in length of stay (LOS), overall complications, and mortality. ${ }^{15-18}$ However, in these reviews, early oral intake did not affect AL. ${ }^{15-18}$ Importantly, these systematic reviews included various types of GI surgery or included studies that combined other elements of fast-track protocols in the intervention group but not in the control group. ${ }^{15-18}$ To further investigate the potential beneficial effects of EN on anastomotic healing, this systematic review

From the ${ }^{1}$ Department of Surgery, Catharina Hospital, Eindhoven, the Netherlands: ${ }^{2}$ GROW School of Oncology and Developmental Biology, Maastricht University, Maastricht, the Netherlands; ${ }^{3}$ Tytgat Institute for Intestinal and Liver Research, Academic Medical Center, Amsterdam, the Netherlands; and the ${ }^{4}$ School for Mental Health and Neuroscience, Maastricht University, Maastricht, Limburg, the Netherlands.

Financial disclosure: None declared.

Conflicts of interest: None declared.

This article originally appeared online on June 19, 2017.

Corresponding Author:

Boudewijn J. J. Smeets, MD, Department of Surgery, Catharina

Hospital Eindhoven, Michelangelolaan 2, Eindhoven, Noord-Brabant 5623 EJ, the Netherlands.

Email: boudewijn.smeets@catharinaziekenhuis.nl 
compares the effect of early vs late start of oral intake on AL following elective lower intestinal surgery.

\section{Methods}

This systematic review was performed according to the Cochrane Handbook for Systematic Reviews for Interventions ${ }^{19}$ and the Preferred Reporting Items for Systematic Reviews and Meta-Analyses (PRISMA) statement guidelines. ${ }^{20}$ The entire review process (ie, article search, critical appraisal, data extraction, and analysis) was conducted by 3 independent researchers (B.J.J.S., E.G.P., and E.C.J.H.). Any disagreements were resolved through discussion.

\section{Eligibility Criteria}

We included only randomized controlled clinical trials that reported on the effects of early vs late start of oral intake on AL following elective surgery of the small bowel, colon, or rectum in patients aged $\geq 18$ years. We defined early start of oral intake as any caloric intake started within 24 hours after surgery. Late start of oral intake was defined as nil by mouth until resolution of postoperative ileus (ie, passage of flatus or stool without presence of nausea or vomiting). To assess the true effect of early oral intake alone, we excluded studies that combined early oral intake with other elements of fast-track protocols in the intervention group but not in the control group.

\section{Information Sources and Search Strategy}

The PubMed, Medline, Embase, and Cochrane databases were systematically searched. The search strategy combined all synonyms regarding the intervention "early oral intake" and the domain "lower intestinal surgery" with the Boolean operator "AND." All synonyms were combined with the Boolean operator "OR." An example set of search terms is provided in Supplementary Table S1. We tested the sensitivity of the search strategy by screening all references of included articles for relevant publications that were not retrieved in the initial search. Furthermore, we screened all citing articles and related articles using Web of Science version 5.15.1. Identification of additional eligible articles led to evaluation and improvement of the search strategy until it retrieved all eligible articles. We contacted authors by email if articles were not available in full text. The search was updated until September 28, 2016.

\section{Study Selection}

Three authors screened all records on title and abstract. Records were excluded if they clearly did not address the domain and intervention under investigation. The remaining articles were screened in full text. Only articles fulfilling all eligibility criteria were included.

\section{Data Extraction and Outcomes}

The relevant published data were collected in pilot-tested tables. Extracted information from each study included (1) study information, including name of first author, year of publication, number of participants in each group, and reported outcomes; (2) patient information, including type of surgery, disease, sex, age, and perioperative protocols used affecting $\mathrm{AL}^{21}$; and (3) postoperative feeding protocols. Furthermore, we extracted data on the incidence and definition of $\mathrm{AL}$, overall complications, mortality, and LOS.

\section{Risk of Bias in Individual Studies}

All studies included in the review were investigated for risk of bias with the Cochrane collaboration's tool for assessing risk of bias. ${ }^{19}$ Risk of bias was assessed on the following items: randomization method, allocation concealment, blinding of participants and personnel, blinding of outcome assessment, incomplete outcome data, selective reporting, and any other item in study design.

\section{Data Analysis}

Meta-analysis was performed for AL, overall complications, LOS, and mortality. We performed data analysis using Review Manager Software version 5.3 as recommended by the Cochrane Handbook for Systematic Reviews for Interventions. ${ }^{19,22}$ Dichotomous results were analyzed using the random-effects model in the Mantel-Haenszel method and are presented as odds ratio (ORs) with corresponding $95 \%$ confidence intervals (CIs). Continuous results were analyzed using the inverse variance method and are presented as mean difference (MD) with corresponding $95 \%$ CI. A $P$ value $<.05$ was considered to be statistically significant. We assessed presence and amount of statistical heterogeneity using the $I^{2}$ statistic. Furthermore, a sensitivity analysis was performed in which studies of inferior methodological quality were excluded.

\section{Results}

\section{Description of Studies}

Figure 1 presents the search results and study selection process. The search revealed 80 potentially relevant studies, of which 9 randomized controlled trials fitted inclusion criteria. Study characteristics are shown in Table 1 . Types of surgical procedures were evenly matched between groups in all studies. Laparoscopic surgery was performed only in 1 study $^{23}$; in other studies, open surgery was performed. ${ }^{24-31}$ When reported, there was substantial heterogeneity between studies in the use of perioperative protocols, including use of epidural anesthesia, preoperative bowel lavage, nonsteroid anti-inflammatory drugs, and 


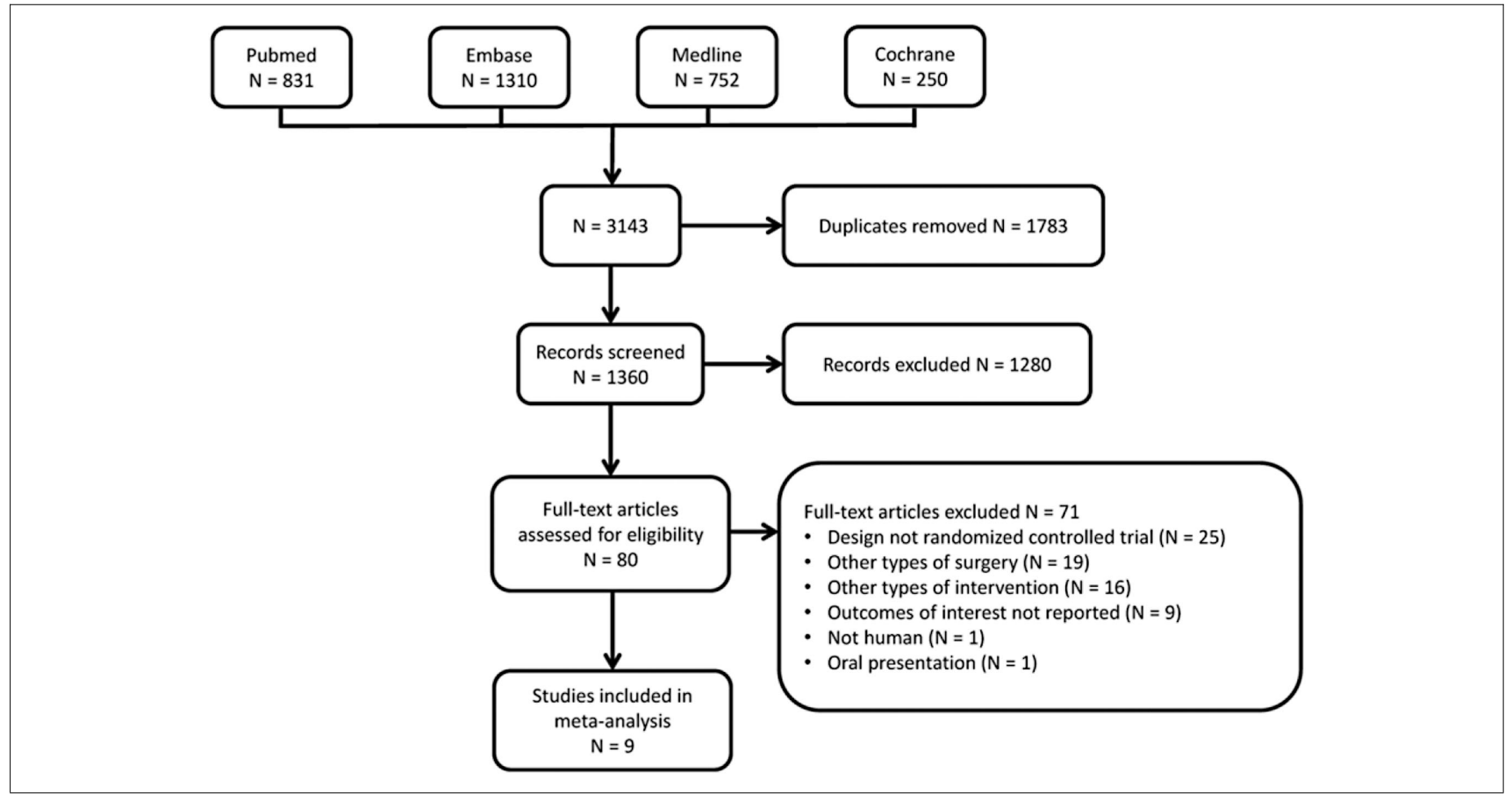

Figure 1. Preferred Reporting Items for Systematic Reviews and Meta-Analyses (PRISMA) flowchart for search results and study selection process.

opioids. Postoperative feeding protocols are described in Table 2.

AL was a rare event in most studies and rarely a primary outcome. Four studies provided definitions for AL (Table 3). ${ }^{25,26,28,31}$

\section{Methodological Quality of Included Studies}

Due to the nature of the intervention, blinding could not be applied in any study. Three studies gave no explicit description of the randomization method, resulting in an unclear risk of bias. ${ }^{26,27,30}$ One open-label study used blocked randomization with a fixed block size of 6; hence, risk of selection bias was present. ${ }^{29}$ In the same study, it was unclear whether the nasogastric tube was postoperatively removed in both groups at similar time points. In 1 study, ${ }^{28}$ patients allocated to delayed start of oral intake had a significantly greater amount of intraoperative blood loss (early oral intake median $300 \mathrm{~mL}$ vs delayed oral intake median $800 \mathrm{~mL}, P=.002$ ), which is a known risk factor for AL. ${ }^{21}$ The summary of risk of bias assessment is shown in Table 4. Overall, 3 studies were identified to have the best available methodological quality and were entered in the sensitivity analysis. ${ }^{23,24,31}$

\section{$A L$}

First, all studies were entered in the meta-analysis regardless of methodological quality. As shown in Figure 2A, early start of oral intake significantly reduced AL compared with late start of oral intake (OR, $0.40 ; 95 \% \mathrm{CI}, 0.17-0.95 ; P=$ $.04)$. However, when trials with risk of bias were excluded in the sensitivity analysis, the overall effect on $\mathrm{AL}$ was no longer significant (OR, 0.39; 95\% CI, 0.09-1.76; $P=.22$ ) (Figure 2B).

\section{Overall Complications}

All studies provided data on overall complications. As shown in Figure 3A, early start of oral intake significantly reduced overall complications compared with late start of oral intake (OR, 0.65; 95\% CI, 0.46-0.93; $P=.02$ ). However, when trials with risk of bias were excluded in the sensitivity analysis, the overall effect on overall complications was no longer significant (OR, 0.74; 95\% CI, 0.42$1.31 ; P=.30$ ) (Figure 3B).

\section{LOS}

Seven studies provided data on LOS as mean \pm standard deviation and were entered in the meta-analysis. ${ }^{23-26,28-30} \mathrm{As}$ shown in Figure 4A, early start of oral intake significantly reduced LOS compared with late start of oral intake (MD, $-0.89 ; 95 \% \mathrm{CI},-1.22$ to $-0.57 ; P<.001)$. Excluding studies with risk of bias increased the overall effect of LOS (MD, $-3.47 ; 95 \% \mathrm{CI},-4.73$ to $-2.21 ; P<.001$ ) (Figure 4B). 


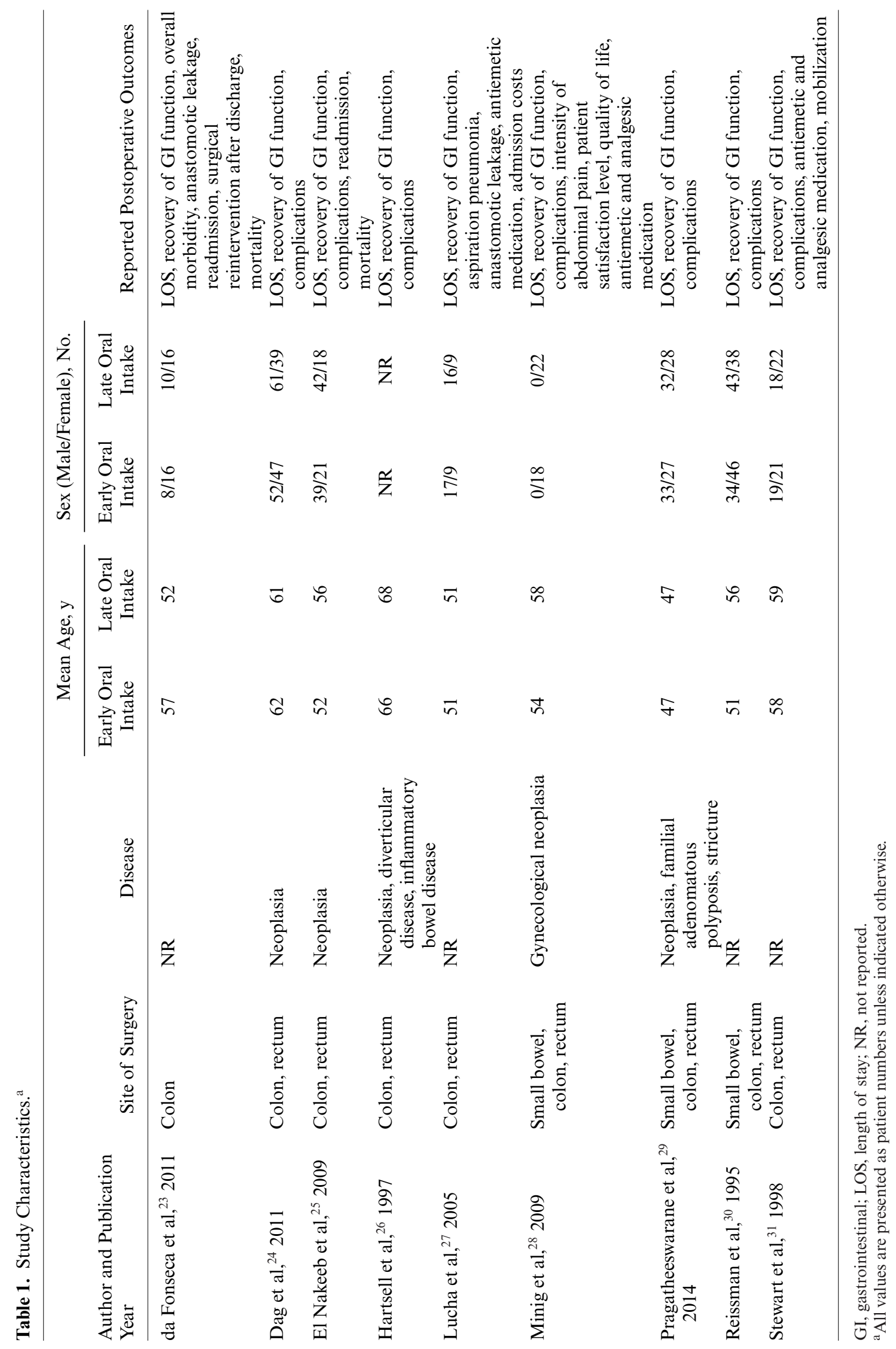


Table 2. Postoperative Feeding Protocols.

\begin{tabular}{|c|c|c|}
\hline $\begin{array}{l}\text { Author and } \\
\text { Publication Year }\end{array}$ & Early Oral Intake & $\begin{array}{l}\text { Late Oral } \\
\text { Intake }\end{array}$ \\
\hline $\begin{array}{l}\text { da Fonseca et al, }{ }^{23} \\
2011\end{array}$ & $\begin{array}{l}\text { POD1 oral liquid diet, } \\
\text { advance to regular diet } \\
\text { within } 24 \text { hours as } \\
\text { tolerated }\end{array}$ & $\mathrm{SC}$ \\
\hline Dag et al, ${ }^{24} 2011$ & $\begin{array}{c}12 \text { hours postoperatively, } \\
\text { start fluids, advance to } \\
\text { solid diet as tolerated }\end{array}$ & $\mathrm{SC}$ \\
\hline $\begin{array}{l}\text { El Nakeeb et al, }{ }^{25} \\
2009\end{array}$ & $\begin{array}{l}\text { POD1 fluids, advance to } \\
\text { regular diet within } \\
24-48 \text { hours as } \\
\text { tolerated }\end{array}$ & $\mathrm{SC}$ \\
\hline Hartsell et al, ${ }^{26} 1997$ & $\begin{array}{l}\text { POD1 full liquid diet, } \\
\text { advance to regular diet } \\
\text { if }>1000 \mathrm{~mL} \text { was } \\
\text { consumed within } 24 \\
\text { hours }\end{array}$ & $\mathrm{SC}$ \\
\hline Lucha et al, ${ }^{27} 2005$ & $\begin{array}{l}8 \text { hours after surgery, } \\
\text { start regular diet }\end{array}$ & $\mathrm{SC}$ \\
\hline Minig et al, ${ }^{28} 2009$ & $\begin{array}{l}\text { POD0 CL, advance to } \\
\text { regular diet on POD1 } \\
\text { as tolerated }\end{array}$ & $\mathrm{SC}$ \\
\hline $\begin{array}{l}\text { Pragatheeswarane et } \\
\text { al, }{ }^{29} 2014\end{array}$ & $\begin{array}{l}\text { POD1 CL, advance to } \\
\text { full fluid diet within } 48 \\
\text { hours, start solid diet } \\
\text { over next } 24 \text { hours }\end{array}$ & $\mathrm{SC}$ \\
\hline Reissman et al, ${ }^{30} 1995$ & $\begin{array}{l}\text { POD1 CL, advance to } \\
\text { regular diet as } \\
\text { tolerated }\end{array}$ & $\mathrm{SC}$ \\
\hline Stewart et al, ${ }^{31} 1998$ & $\begin{array}{l}4 \text { hours postoperatively, } \\
\text { start free fluids, } \\
\text { advance to solid diet } \\
\text { as tolerated on POD1 }\end{array}$ & $\mathrm{SC}$ \\
\hline
\end{tabular}

CL, clear liquids; POD, postoperative day; SC, standard care (nil by mouth until resolution of ileus).

\section{Mortality}

Seven studies provided data on mortality and were entered in the meta-analysis. ${ }^{23,25,26,28-31}$ As shown in Figure 5A, early start of oral intake did not affect mortality compared with late start of oral intake (OR, $0.61 ; 95 \% \mathrm{CI}, 0.17-2.22 ; P=$ .45). Excluding studies with risk of bias did not alter the overall effect of early start of oral intake on mortality (OR, $1.04 ; 95 \%$ CI, 0.10-10.35; $P=.97$ ) (Figure 5B).

\section{Discussion}

The current review demonstrates that the effect of early oral intake on $\mathrm{AL}$ is unclear in a clinical setting. This is mainly due to a lack of high-quality evidence, since existing randomized trials are clinically heterogeneous and at risk of bias.
Table 3. Definitions for Anastomotic Leakage.

\begin{tabular}{lc}
\hline $\begin{array}{l}\text { Author and Publication } \\
\text { Year }\end{array}$ & \multicolumn{1}{c}{ Definition } \\
\hline El Nakeeb et al, ${ }^{25} 2009$ & $\begin{array}{c}\text { Symptoms such as fever and } \\
\text { leakage of intestinal contents } \\
\text { Resulting in sepsis and eventual } \\
\text { death }\end{array}$ \\
Hartsell et al, ${ }^{26} 1997$ & $\begin{array}{l}\text { Requiring surgical reexploration } \\
\text { Minig et al, }{ }^{28} \text { 2009 }\end{array}$ \\
Stewart et al, ${ }^{31} 1998$ & $\begin{array}{c}\text { Fhich settled without } \\
\text { intervention }\end{array}$ \\
\hline
\end{tabular}

Experimental studies have suggested that EN can improve anastomotic healing via several mechanisms. ${ }^{6-12}$ These experimental findings may be corroborated by 2 randomized clinical trials of good methodological quality that demonstrated a reduction of AL by means of perioperative sham feeding ${ }^{14}$ (ie, gum-chewing) and early postoperative enteral tube feeding. ${ }^{13}$ Early start of oral intake is a more common form of early EN and has been extensively described as part of fast-track protocols in colorectal surgery. Individual randomized trials have described no effect of early oral intake on AL, but most studies had a relatively small sample size and were therefore inadequately powered to detect a potential effect on AL. ${ }^{23-31}$ Previous systematic reviews on early EN also did not support an effect on AL. ${ }^{15-18}$ However, these reviews may have been inadequate to assess the true effect of EN, since they included studies with patients undergoing upper GI surgery, ${ }^{32}$ studies that applied immunonutrition, ${ }^{33}$ or studies that applied other aspects of fast-track protocols only in the treatment group but not in the control group (eg, early nasogastric tube removal). ${ }^{34}$ Furthermore, no review performed a sensitivity analysis to minimize the risk of bias. ${ }^{15-18}$ This study therefore aimed to provide an update of the available literature and to perform a rigorous critical appraisal and sensitivity analysis to examine the true effect of EN on anastomotic healing in a clinical setting. In the current meta-analysis, the pooling of all 9 randomized trials regardless of methodological quality resulted in several beneficial effects in favor of early oral intake. However, the strict exclusion of 6 studies with a modest to high risk of bias ${ }^{25-30}$ in the sensitivity analysis significantly reduced overall sample size and made the effect on AL and overall complications no longer significant. As such, the results from our study suggest that early start of oral intake is only associated with a reduction of length of stay (LOS).

The overall reduction of LOS following early oral intake ranges from almost 1 day in the general meta-analysis to approximately 3 days in the sensitivity analysis. This may be explained by a faster return of bowel function in the early feeding group, as demonstrated by various indicators 


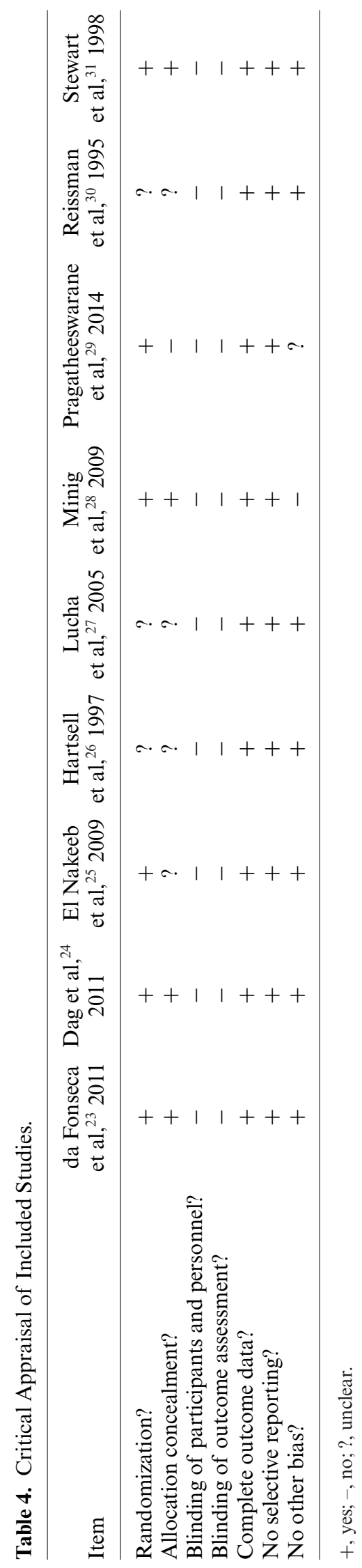




\section{A}

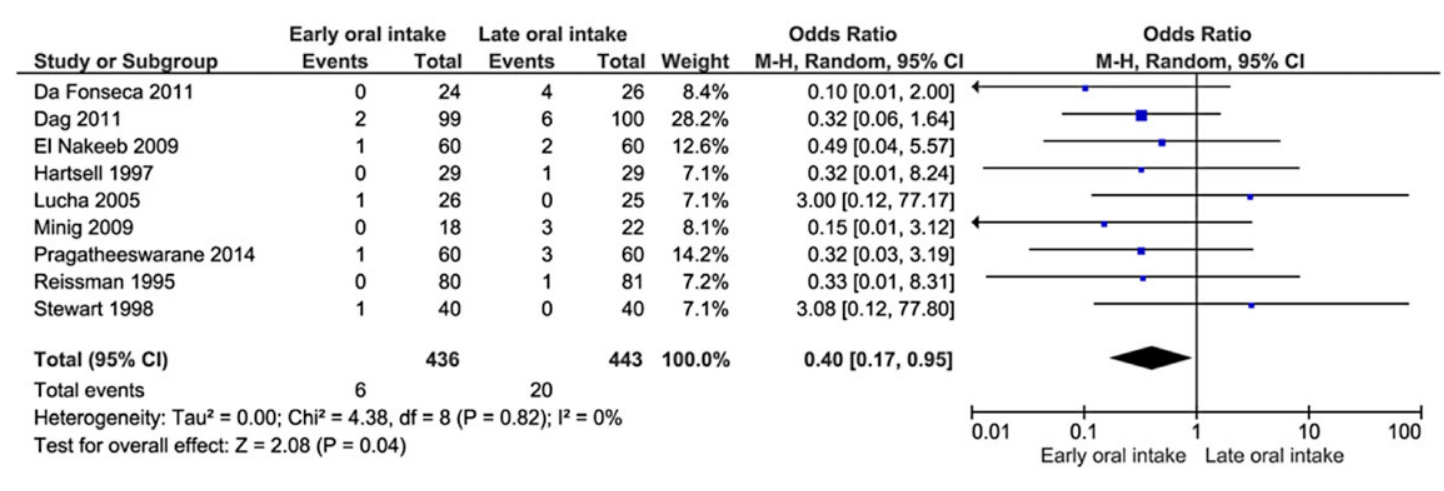

B

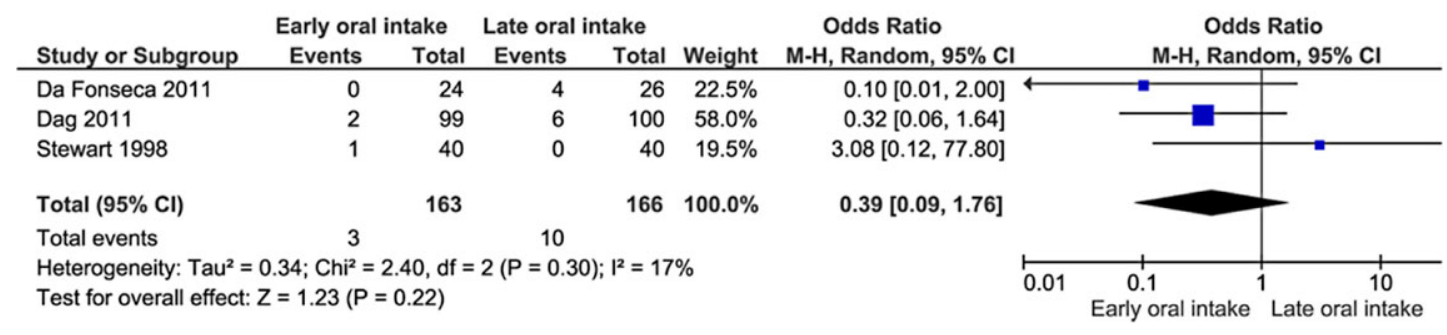

Figure 2. (A) Forest plot for studies that examined the effect of early vs late start of oral intake for anastomotic leakage. (B) Sensitivity analysis for studies that examined the effect of early vs late start of oral intake for anastomotic leakage. M-H, Mantel-Haenszel.

\begin{tabular}{|c|c|c|c|c|c|}
\hline \multirow[b]{2}{*}{ Study or Subgroup } & \multicolumn{2}{|c|}{ Early oral intake } & \multicolumn{2}{|c|}{ Late oral intake } & \multirow[b]{2}{*}{ Weight } \\
\hline & Events & Total & Events & Total & \\
\hline Da Fonseca 2011 & 4 & 24 & 9 & 26 & $6.9 \%$ \\
\hline Dag 2011 & 12 & 99 & 14 & 100 & $18.3 \%$ \\
\hline El Nakeeb 2009 & 14 & 60 & 22 & 60 & $19.8 \%$ \\
\hline Hartsell 1997 & 1 & 29 & 1 & 29 & $1.6 \%$ \\
\hline Lucha 2005 & 1 & 26 & 1 & 25 & $1.6 \%$ \\
\hline Minig 2009 & 8 & 18 & 12 & 22 & $8.0 \%$ \\
\hline Pragatheeswarane 2014 & 29 & 60 & 40 & 60 & $23.0 \%$ \\
\hline Reissman 1995 & 6 & 80 & 5 & 81 & $8.3 \%$ \\
\hline Stewart 1998 & 10 & 40 & 11 & 40 & $12.6 \%$ \\
\hline Total $(95 \% \mathrm{Cl})$ & & 436 & & 443 & $100.0 \%$ \\
\hline Total events & 85 & & 115 & & \\
\hline \multicolumn{6}{|c|}{ Heterogeneity: $\mathrm{Tau}^{2}=0.00 ; \mathrm{Chi}^{2}=3.62, \mathrm{df}=8(\mathrm{P}=0.89) ; \mathrm{I}^{2}=0 \%$} \\
\hline
\end{tabular}

Odds Ratio

, Random, 95\% Cl

$0.38[0.10,1.45]$

$0.85[0.37,1.94]$

$0.53[0.24,1.17]$

$1.00[0.06,16.79]$

$0.96[0.06,16.23]$

$0.67[0.19,2.33]$

$0.47[0.22,0.98]$

$1.23[0.36,4.21]$

$0.88[0.32,2.38]$

$0.65[0.46,0.93]$

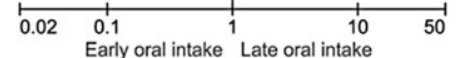

B

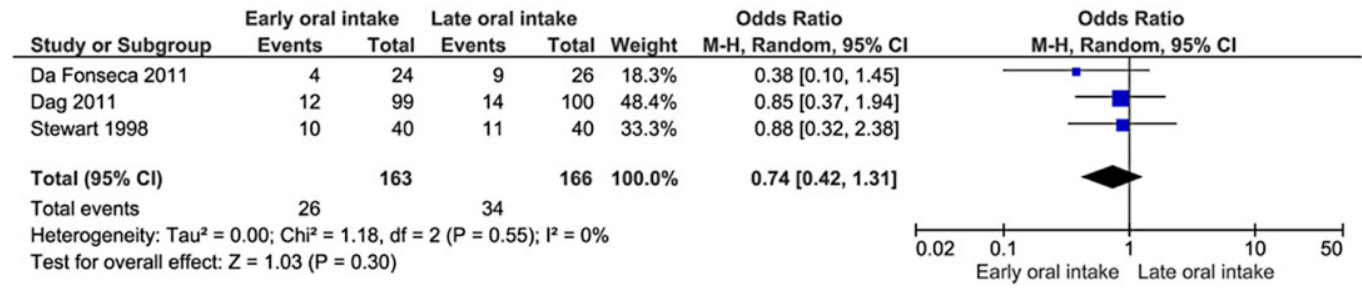

Figure 3. (A) Forest plot for studies that examined the effect of early vs late start of oral intake for overall complications. (B) Sensitivity analysis for studies that examined the effect of early vs late start of oral intake for overall complications. M-H, Mantel-Haenszel. 


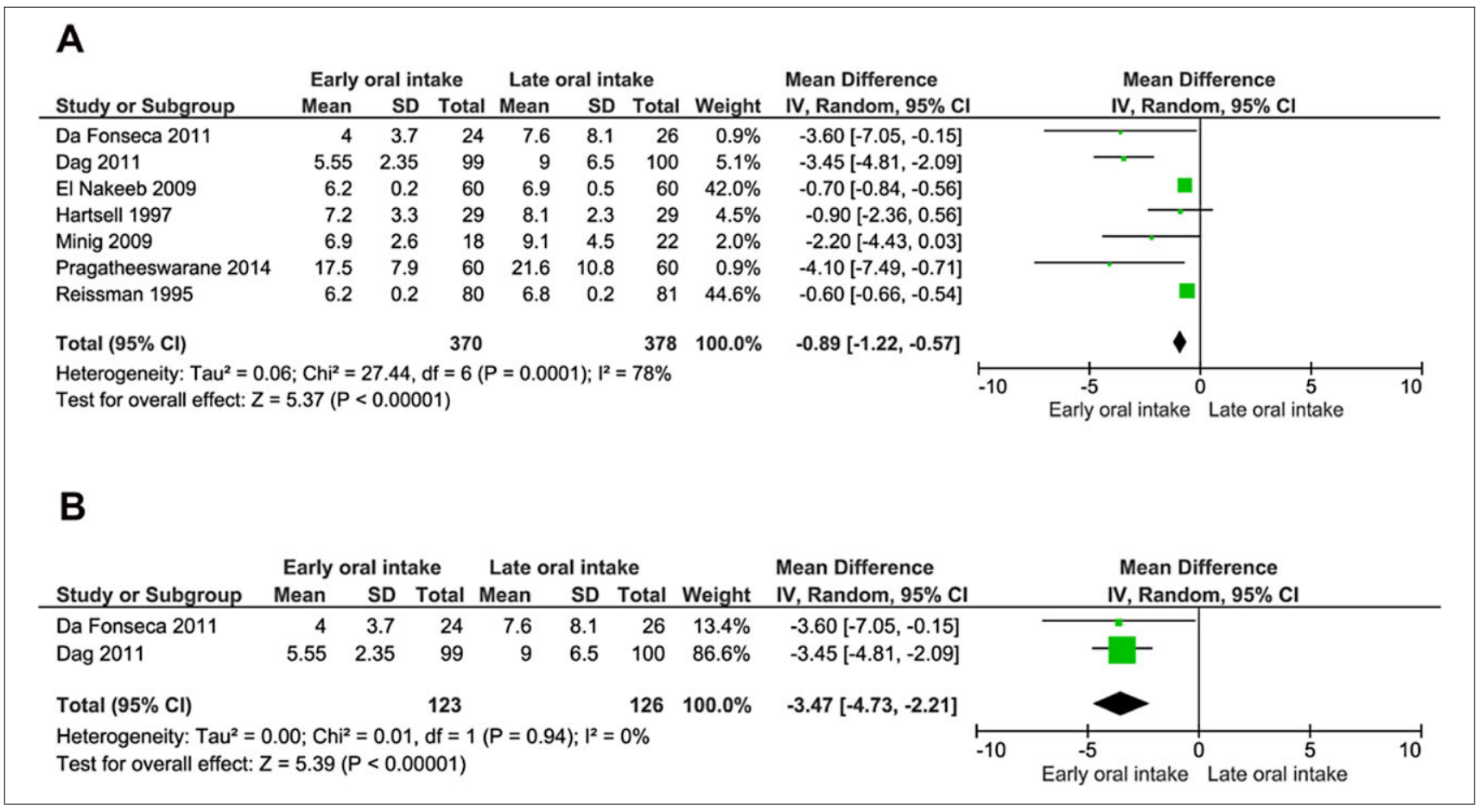

Figure 4. (A) Forest plot for studies that examined the effect of early vs late start of oral intake for length of stay. (B) Sensitivity analysis for studies that examined the effect of early vs late start of oral intake for length of stay. IV, inverse variance; M-H, Mantel-Haenszel.

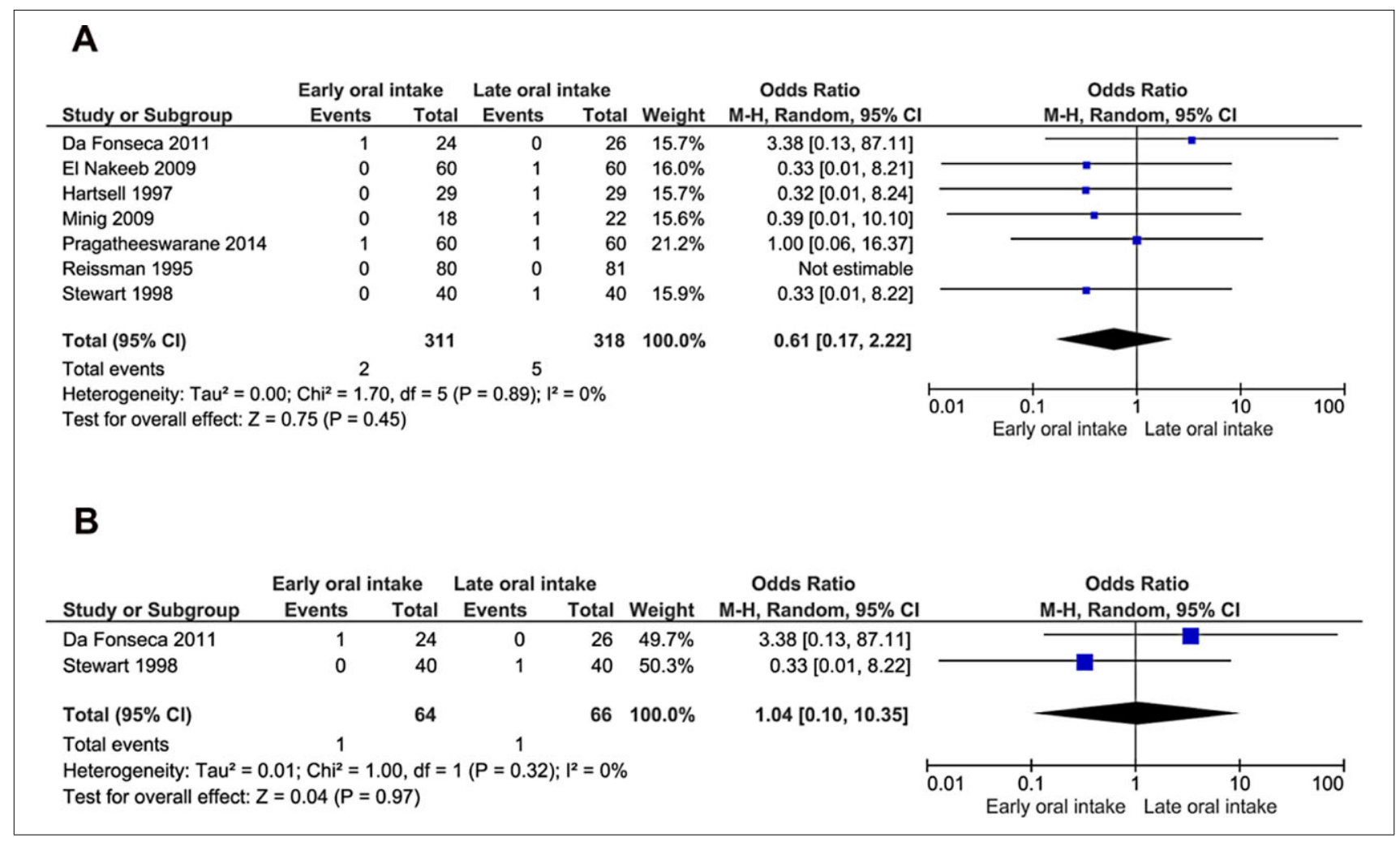

Figure 5. (A) Forest plot for studies that examined the effect of early vs late start of oral intake for mortality. (B) Sensitivity analysis for studies that examined the effect of early vs late start of oral intake for mortality. M-H, Mantel-Haenszel. 
of GI motility (eg, time to first flatus or defecation) in multiple studies. ${ }^{23-25,29}$ However, differences in discharge criteria between the included studies may have confounded the effect of early oral intake on LOS, as suggested by the high statistical heterogeneity.

Despite the attempt to minimize risk of bias by means of a sensitivity analysis, several other limitations remain present in the current systematic review. First, perioperative protocols varied greatly between studies, including the use of nonsteroid anti-inflammatory drugs and preoperative bowel lavage. However, while differences in these protocols can affect various clinical outcomes, the specific effect on AL may be limited except for nonsteroid anti-inflammatory drugs. ${ }^{21}$ Second, no study was blinded; however blinding is difficult to apply due to the nature of the intervention. Third, the included studies involved various sites of lower intestinal surgery; it is well known that the a priori risks of AL vary in the small bowel, colon, and rectum. However, in the sensitivity analysis, only studies including colorectal surgery were included. Last, a clear definition for AL lacked in most studies and varied between studies when provided. While this review attempts to summarize best available evidence, the generalizability remains limited by the heterogeneity of the included studies.

In conclusion, the results of this systematic review suggest that early oral intake is associated with a reduction in LOS, while the effect on anastomotic healing remains unclear as existing literature is clinically heterogeneous and at risk of bias. More well-designed, high-quality randomized studies are needed to further study the potential benefit of $\mathrm{EN}$, since alternative strategies that reduce $\mathrm{AL}$ are lacking.

\section{Statement of Authorship}

B. J. J. Smeets and M. D. P. Luyer equally contributed to the conception and design of the research; T. J. Weijs contributed to the design of the research; and B. J. J. Smeets, E. G. Peters, and E. C. J. Horsten contributed to the acquisition and analysis of the data and drafted the manuscript. All authors contributed to the interpretation of the data, critically revised the manuscript, agree to be fully accountable for ensuring the integrity and accuracy of the work, and read and approved the final manuscript.

\section{Supplementary Information}

Additional supporting information may be found online in the Supporting Information section at the end of the article.

\section{References}

1. Jannasch $\mathrm{O}$, Klinge $\mathrm{T}$, Otto $\mathrm{R}$, et al. Risk factors, short and long term outcome of anastomotic leaks in rectal cancer. Oncotarget. 2015;6(34):36884-36893

2. Kang CY, Halabi WJ, Chaudhry OO, et al. Risk factors for anastomotic leakage after anterior resection for rectal cancer. JAMA Surg. 2013;148(1):65-71.
3. Krarup PM, Nordholm-Carstensen A, Jorgensen LN, Harling H Anastomotic leak increases distant recurrence and long-term mortality after curative resection for colonic cancer: a nationwide cohort study. Ann Surg. 2014;259(5):930-938.

4. Mirnezami A, Mirnezami R, Chandrakumaran K, Sasapu K, Sagar $P$, Finan P. Increased local recurrence and reduced survival from colorectal cancer following anastomotic leak: systematic review and meta-analysis. Ann Surg. 2011;253(5):890-899.

5. Daams F, Luyer M, Lange JF. Colorectal anastomotic leakage: aspects of prevention, detection and treatment. World J Gastroenterol. 2013;19(15):2293-2297.

6. Demetriades H, Botsios D, Kazantzidou D, et al. Effect of early postoperative enteral feeding on the healing of colonic anastomoses in rats: comparison of three different enteral diets. Eur Surg Res. 1999;31(1):57-63.

7. Guven A, Pehlivan M, Gokpinar I, Gurleyik E, Cam M. Early glutamine-enriched enteral feeding facilitates colonic anastomosis healing: light microscopic and immunohistochemical evaluation. Acto Histochem. 2007;109(2):122-129.

8. Khalili TM, Navarro RA, Middleton Y, Margulies DR. Early postoperative enteral feeding increases anastomotic strength in a peritonitis model. Am J Surg. 2001;182(6):621-624.

9. Fukuzawa J, Terashima H, Ohkohchi N. Early postoperative oral feeding accelerates upper gastrointestinal anastomotic healing in the rat model. World J Surg. 2007;31(6):1234-1239.

10. Tadano S, Terashima H, Fukuzawa J, Matsuo R, Ikeda O, Ohkohchi $\mathrm{N}$. Early postoperative oral intake accelerates upper gastrointestinal anastomotic healing in the rat model. $J$ Surg Res. 2011;169(2):202-208.

11. Kiyama T, Efron DT, Tantry U, Barbul A. Effect of nutritional route on colonic anastomotic healing in the rat. $J$ Gastrointest Surg. 1999;3(4):441-446.

12. Kiyama T, Onda M, Tokunaga A, Yoshiyuki T, Barbul A. Effect of early postoperative feeding on the healing of colonic anastomoses in the presence of intra-abdominal sepsis in rats. Dis Colon Rectum. 2000;43(10)(suppl):S54-S58.

13. Boelens PG, Heesakkers FF, Luyer MD, et al. Reduction of postoperative ileus by early enteral nutrition in patients undergoing major rectal surgery: prospective, randomized, controlled trial. Ann Surg. 2014;259(4):649-655.

14. van den Heijkant TC, Costes LM, van der Lee DG, et al. Randomized clinical trial of the effect of gum chewing on postoperative ileus and inflammation in colorectal surgery. Br J Surg. 2015;102(3):202-211.

15. Andersen HK, Lewis SJ, Thomas S. Early enteral nutrition within $24 \mathrm{~h}$ of colorectal surgery versus later commencement of feeding for postoperative complications. Cochrane Database Syst Rev. 2006;(4):CD004080.

16. Lewis SJ, Andersen HK, Thomas S. Early enteral nutrition within $24 \mathrm{~h}$ of intestinal surgery versus later commencement of feeding: a systematic review and meta-analysis. J Gastrointest Surg. 2009;13(3):569-575.

17. Osland E, Yunus R, Khan S, Memon MA. Early enteral nutrition within $24 \mathrm{~h}$ of intestinal surgery versus later commencement of feeding: a systematic review and meta-analysis. $J$ Gastrointest Surg. 2009;13(6):1163-1167

18. Zhuang CL, Ye XZ, Zhang CJ, Dong QT, Chen BC, Yu Z. Early versus traditional postoperative oral feeding in patients undergoing elective colorectal surgery: a meta-analysis of randomized clinical trials. Digest Surg. 2013;30(3):225-232.

19. Higgins JPT, Green S. Cochrane Handbook for Systematic Reviews of Interventions. Version 5.1.0 [updated March 2011]. Chichester, United Kingdom: The Cochrane Collaboration; 2011. http://www. cochrane-handbook.org. Accessed February 13, 2017.

20. Moher D, Liberati A, Tetzlaff J, Altman DG ; PRISMA Group. Preferred reporting items for systematic reviews and meta-analyses: the PRISMA statement. J Clin Epidemiol. 2009;62(10):1006-1012. 
21. McDermott FD, Heeney A, Kelly ME, Steele RJ, Carlson GL, Winter DC. Systematic review of preoperative, intraoperative and postoperative risk factors for colorectal anastomotic leaks. Br J Surg. 2015;102(5):462-479.

22. Review Manager (RevMan) [Computer program]. Version 5.3. Copenhagen, Denmark: The Nordic Cochrane Centre, The Cochrane Collaboration; 2014.

23. da Fonseca LM, Profeta da, Luz MM, Lacerda-Filho A, Correia MI, Gomes da, Silva R. A simplified rehabilitation program for patients undergoing elective colonic surgery - randomized controlled clinical trial. Int J Colorectal Dis. 2011;26(5):609-616.

24. Dag A, Colak T, Turkmenoglu O, Gundogdu R, Aydin S. A randomized controlled trial evaluating early versus traditional oral feeding after colorectal surgery. Clinics. 2011;66(12):2001-2005.

25. El Nakeeb A, Fikry A, El Metwally T, et al. Early oral feeding in patients undergoing elective colonic anastomosis. Int J Surg. 2009;7(3):206-209.

26. Hartsell PA, Frazee RC, Harrison JB, Smith RW. Early postoperative feeding after elective colorectal surgery. Arch Surg. 1997;132(5):518521.

27. Lucha PA Jr, Butler R, Plichta J, Francis M. The economic impact of early enteral feeding in gastrointestinal surgery: a prospective survey of 51 consecutive patients. Am Surg. 2005;71(3):187-190.
28. Minig L, Biffi R, Zanagnolo V, et al. Early oral versus "traditional" postoperative feeding in gynecologic oncology patients undergoing intestinal resection: a randomized controlled trial. Ann Surg Oncol. 2009;16(6):1660-1668.

29. Pragatheeswarane M, Muthukumarassamy R, Kadambari D, Kate V. Early oral feeding vs. traditional feeding in patients undergoing elective open bowel surgery - a randomized controlled trial. $J$ Gastrointest Surg. 2014;18(5):1017-1023.

30. Reissman P, Teoh TA, Cohen SM, Weiss EG, Nogueras JJ, Wexner SD. Is early oral feeding safe after elective colorectal surgery? A prospective randomized trial. Ann Surg. 1995;222(1):73-77.

31. Stewart BT, Woods RJ, Collopy BT, Fink RJ, Mackay JR, Keck JO. Early feeding after elective open colorectal resections: a prospective randomized trial. Aust N Z J Surg. 1998;68(2):125128.

32. Beier-Holgersen R, Boesby S. Influence of postoperative enteral nutrition on postsurgical infections. Gut. 1996;39(6):833-835.

33. Heslin MJ, Latkany L, Leung D, et al. A prospective, randomized trial of early enteral feeding after resection of upper gastrointestinal malignancy. Ann Surg. 1997;226(4):567-580.

34. Ortiz H, Armendariz P, Yarnoz C. Is early postoperative feeding feasible in elective colon and rectal surgery? Int $J$ Colorectal Dis. 1996;11(3):119-121. 